Available online on 15.11.2018 at http://ujpr.org
Universal Journal of Pharmaceutical Research
On International Peer Reviewed Journal
Open access to Pharmaceutical research is an open access article distributed under the terms of the Creative Commons Attribution-Non
Commercial Share Alike 4.0 License which permits unrestricted non commercial use,
provided the original work is properly cited
Volume 3, Issue 5, 2018

\title{
A CROSS-SECTIONAL STUDY ON BENZODIAZIPINE (BZD) ABUSERS OF DHAKA CITY: A SOCIO-PSYCHOLOGICAL CONDITION OF BANGLADESH Forhad Monjur ${ }^{1}\left(\mathbb{D}\right.$, Farhana Rizwan ${ }^{2,3}$ \\ ${ }^{1}$ Department of Clinical Pathology, Institute of Child Health and Shishu Sasthya Foundation Hospital, 6/2, Barabagh, Mirpur-2, Dhaka-1216, Bangladesh. \\ ${ }^{2}$ Department of Pharmaceutical Technology, Jadavpur University, Kolkata-700032, India. \\ ${ }^{3}$ Department of Pharmacy, East West University, A/2, Jahurul Islam City, Aftabnagar, Dhaka-1212, Bangladesh.
}

\section{ABSTRACT}

Objective: Benzodiazepines (BZD) are highly potential drug for abuse among the most frequently prescribed medicine. Different studies say that young-adults are the vulnerable population of BZD misuse in Bangladesh. The aim of the study was designed to evaluate the BZD drug abuser with relation to its impact on socio-psychological condition of Dhaka city.

Methods: A cross sectional study consisted of 468 current BZD users. The participants were chosen randomly. Structured questionnaires included participant's personal information; drug use characteristics; physiological and psychological effects of drugs. Verbal consent was taken from each respondent. In this study, $96.15 \%$ were male where $40.39 \%$ of respondents were from the age group 23-27 years. $57.70 \%$ participants were single. Here, $34.62 \%$ were student, $40.38 \%$ had monthly family income above 50,000 BDT. BZD was used to relive from stress/pressure by $23.07 \%$, from insomnia by $13.46 \%$ of respondents. The drug of choice was diazepam for $44.24 \%$ respondents.

Results: Most of the users (44.23\%) were influenced by friends. 32.69\% participant concomitantly used BZD with YABA. The common problem was amnesia, confusion and difficulty in cognition. The withdrawal effects were rebound insomnia, anxiety, headache; restlessness and so on.

Conclusion: Drug abuse is a serious public health problem worldwide. Therefore, these findings may help Government or policymakers to take initiative for drug addict. Moreover, there is need of further research on these topics in different area of Bangladesh to get the complete scenario of drug abuse, especially BZD abuse.

Keywords: Benzodiazepines (BZD), drug abuser, drug misuse, withdrawal effects.

Article Info: Received 2 September 2018; Revised 8 October; Accepted 5 November, Available online 15 November 2018
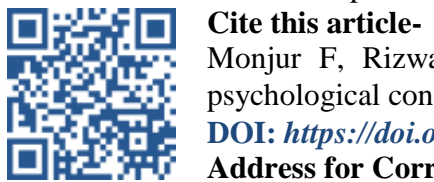

Monjur F, Rizwan F. A cross-sectional study on Benzodiazipine (bzd) abusers of Dhaka city: A sociopsychological condition of Bangladesh. Universal Journal of Pharmaceutical Research 2018; 3(5): 11-15.

DOI: https://doi.org/10.22270/ujpr.v3i5.196

Address for Correspondence

Dr. Forhad Monjur, Associate Professor and Head, Department of Clinical Pathology, Institute of Child Health and Shishu Sasthya Foundation Hospital, 6/2, Barabagh, Mirpur-2, Dhaka-1216, Bangladesh. Tel: +880-1978134520, E-mail: monjur_forhad@yahoo.com

\section{INTRODUCTION}

Benzodiazepines (BZD) are psychoactive drugs, used to treat anxiety and sleep disorders as a first line drug therapy. Anxiolytic, sedative, hypnotic, anticonvulsant, muscle relaxants are common pharmacological actions. Generally, it is prescribed to the patient in a low to medium doses. Though BZD are central nervous system depressants, inappropriate and unnecessary uses can cause physical and psychological dependence, which is related to public health issue ${ }^{1}$. Misuse and abuse of BZD is a serious public health problem in Bangladesh, now a day. Many Pharmaceutical Industries manufacturing BZD in large scale and distributes all over Bangladesh. Expert says that the main illicit drugs are cannabis, heroin and amphetamine-type stimulants (Yaba) in Bangladesh ${ }^{2}$. However, there is no recent authentic source of data to assess the severity of the problem and the associated factors of BZD misuse. A study conducted by the International Centre for Diarrhoeal Disease Research, Bangladesh (ICDDR, B) shows that $79.4 \%$ of the drug users are male in Dhaka city, $64.8 \%$ of the drug users are unmarried, $56.1 \%$ are either students or unemployed, and $95.4 \%$ are smokers. $85.7 \%$ get into consuming drugs under the influence of friends, while $65.8 \%$ get addicted to various codeine-laced cough syrups in Bangladesh ${ }^{3}$. Misuse of Pharmaceutical is a relatively international experience. Among the most frequently prescribed psychotropic drug, BZD is in top in the world. In USA, South Asia and in Africa, BZD 
abuse has reached in alarming position ${ }^{2}$. In Western Europe and North America, use of illicit substances becomes a great concern for large numbers of young people. Moreover, in UK, rate of alcohol and drug users are higher than those reported in outside of Europe $^{4}$. World Drug Report in 2006 mentioned the non medical use of BZD abuse and dependence remains serious problems in many countries with social and economic consequences ${ }^{5}$. As drug abuse is directly related to the socio economic condition of many countries, so this study was designed to collect some data that will help regulatory authority to focus on particular issue.

\section{MATERIALS AND METHODS}

\section{Study design and Study Population}

A cross sectional study was done among the BZD users. Where data was collected through face-to-face interviews with a structured questionnaire. The target population were all those who used non-prescription drugs BZD alone or with other drugs. A total number of 468 participants, who were living in different area of Dhaka city, were included in this study. The age range of the participants was 18-37 years old. The duration of collecting data was 2 years (from January, 2015 to December, 2016). Participants were randomly chosen. As the research focuses on sedative-hypnotics (BZD) drug users, so researcher had to take the support from dispensary, drug seller, sometimes doctors, rehabilitation centers to get the study sample. Personal communication was also played an important role to conduct the study.

\section{Data collection method}

The structured questionnaire had different segments and accordingly interviewed to participants. The respondents were asked to give the detail information regarding socio-demographic profile with smoking habit. Then asked for participants' chronic disease, frequency and duration of drug use, purpose of the drug use, name of the drug use, history of multiple drug use and recommended by whom etc. Then also asked for problems (physical and psychological) faced in current context after taking the drug, and withdrawal effect. This paper consisted of multiple choice and open answer question. After explaining the purpose of the study to the respondents individually and observed about their willingness to participate and with their verbal consent, the researcher interviewed all the respondents by asking questions in Bengali and completing the question paper in English.

\section{Statistical analysis}

All the data were checked after collection. Then data were entered into computer from paper format and results were calculated with Microsoft ${ }^{\circledR}$ Excel (972003).

\section{RESULTS}

Socio-demographic profile of respondents

Table: 1 shows the socio-demographic characteristics of the respondents. Out of 468 respondents, 96.15\% were male and $3.85 \%$ were female. Most of the respondents $(40.39 \%$ and $36.54 \%)$ were coming from the age group 23-27 and 28-32 years. Single respondents were $57.70 \%$ and married were $40.38 \%$. The educational qualification of the respondents was maximum in University level $(48.08 \%$, either completed the course or continuing), then $25 \%$ respondents were from higher secondary level and $1.92 \%$ was illiterate. Out of 468 participants, student respondents were $34.62 \%$ and $28.85 \%$ were in service and $17.31 \%$ were business people. Therefore, we can say that most of the respondents didn't have any financial crisis. Above 50,000 (BDT) were monthly family income of the $40.38 \%$ respondents. Then, $13.46 \%$ respondents have monthly family income was 10,000-20,000 (BDT).

Table 1: Socio-demographic profile and smoking habit of the respondents.

\begin{tabular}{|c|c|c|}
\hline $\begin{array}{l}\text { Different } \\
\text { Variables }\end{array}$ & Frequency & $\begin{array}{c}\text { Percentage } \\
(\%)\end{array}$ \\
\hline \multicolumn{3}{|c|}{ Gender } \\
\hline Male & 450 & 96.15 \\
\hline Female & 18 & 3.85 \\
\hline \multicolumn{3}{|c|}{ Age Group } \\
\hline $18-22$ & 81 & 17.31 \\
\hline $23-27$ & 189 & 40.39 \\
\hline $28-32$ & 171 & 36.54 \\
\hline $33-37$ & 27 & 5.76 \\
\hline \multicolumn{3}{|c|}{ Marital Status } \\
\hline Single & 270 & 57.70 \\
\hline Married & 189 & 40.38 \\
\hline Divorced & 9 & 1.92 \\
\hline \multicolumn{3}{|c|}{ Level of Education } \\
\hline Primary & 36 & 7.69 \\
\hline School & 81 & 17.31 \\
\hline College & 117 & 25.00 \\
\hline University & 225 & 48.08 \\
\hline Illiterate & 9 & 1.92 \\
\hline \multicolumn{3}{|c|}{ Occupation } \\
\hline Student & 162 & 34.62 \\
\hline Service & 135 & 28.85 \\
\hline Business & 81 & 17.31 \\
\hline $\begin{array}{l}\text { Garment } \\
\text { worker }\end{array}$ & 45 & 9.61 \\
\hline Unemployed & 36 & 7.68 \\
\hline Housewife & 9 & 1.92 \\
\hline \multicolumn{3}{|c|}{ Monthly Family Income (BDT) } \\
\hline Below 10000 & 36 & 7.69 \\
\hline $10000-20000$ & 63 & 13.46 \\
\hline $20000-35000$ & 90 & 1.92 \\
\hline $25000-50000$ & 90 & 1.92 \\
\hline Above 50000 & 189 & 40.38 \\
\hline \multicolumn{3}{|c|}{ Smoking } \\
\hline Non-smoker & 207 & 44.23 \\
\hline Smoker & 153 & 32.69 \\
\hline Chain-smoker & 108 & 23.08 \\
\hline
\end{tabular}

\section{Health Status of the Respondents}

More than half $(55.77 \%, 261 / 468)$ of the drug users were smoker $(32.69 \%, 153 / 468)$ and chain smoker (23.08\%, 108/468) (Table: 1). Among all the participants, $76.92 \%$ had no chronic disease. Hypertension, GIT disorder and diabetes mellitus was found $13.47 \%, 7.69 \%$ and $1.92 \%$ of the participants respectively. Figure: 1 presented the remarkable number of side effects when the users started to taking BZD. Each of 54 users had confusion and fatigue, each 
of 45 users had anxiety and drowsiness, 36 users had insomnia, 27 users had constipation, 18 users had some other side effects and no side effects were found in majority number of respondents $(n=189)$.

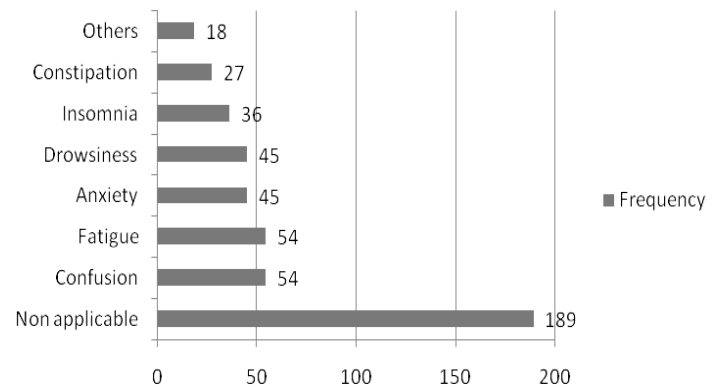

Figure 1: Different side effects of the respondents.

Drug use characteristics of respondents

Most of the respondents $(23.07 \%, 108 / 468)$ were taken drug to relieve from stress/pressure, 63(13.46\%) were taken to relieve from insomnia, 63(13.46\%) were taken to increase the working activity, 54(11.53\%) were taken to increase their confidence level, 45(9.61\%) were taken to get sound sleep, 36(7.69\%) of each were taken for relieve anxiety, depression and to get pleasure; $27(5.76 \%)$ were taken the drug for no reason. Figure 2 presents the percentage of the different drugs taking by the respondents.

Table 2: Intake of BZD with other illicit drugs.

\begin{tabular}{lcc}
\hline Other drugs & Frequency & Percentage \\
\hline None & 108 & 23.07 \\
Alcohol & 81 & 17.30 \\
YABA & 153 & 32.69 \\
Marijuana & 99 & 21.15 \\
Phensedyl & 27 & 5.76 \\
\hline
\end{tabular}

Majority were taken diazepam (44.24\%), then clonazepam $(19.24 \%)$, then bromazepam $(13.47 \%)$ and so on. In daily basis, $99(21.15 \%)$ respondents were taken drugs, $81(17.31 \%)$ were taken almost daily, $108(23.08 \%)$ were taken according to their need and highest respondents $135(28.85 \%)$ were taken drugs three times in a week. Lastly, there was no fixed time for $9(1.92 \%)$ respondents to take drug. Maximum 48 months and minimum 6 months, were the duration for taking drugs by the respondents are shown in (Figure 3).

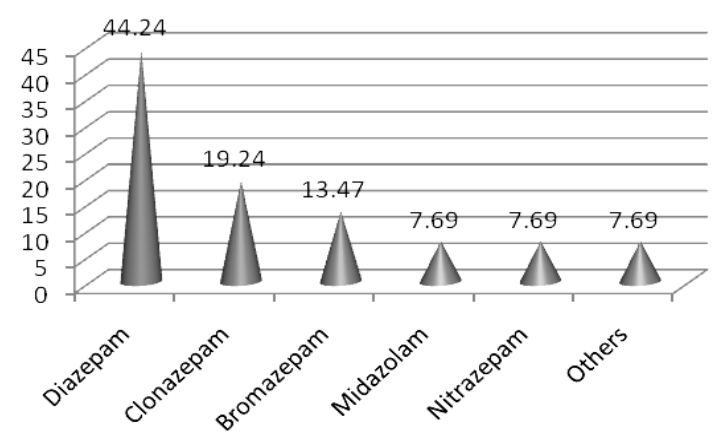

Figure 2: Uses of different drugs by Respondents.
Most of the drug users were influenced by friends $(44.23 \%, 207 / 468)$, recommended by doctor $(11.54 \%$, $54 / 468)$, by verbal communication with medicine seller/pharmacist $(9.60 \%, 50 / 468)$, by their colleague $(3.85 \%, 18 / 468)$ and by their family member $(3.85 \%$, $18 / 468)$. Self medication was done by $(19.23 \%$, 90/468) respondents.

Table 3: Withdrawal effects of the respondents.

\begin{tabular}{lcc}
\hline Variables & Frequency & Percentage \\
\hline \multicolumn{1}{l}{ Try to withdrawal } & & \\
\hline Tried & 432 & 92.30 \\
Never tried & 36 & 7.69 \\
\hline \multicolumn{2}{l}{ Withdrawal effect $(\mathbf{n = 4 3 2 )}$} & \\
\hline Insomnia & 81 & 17.30 \\
Headache & 63 & 13.46 \\
Restlessness & 54 & 11.53 \\
Anxiety & 45 & 9.61 \\
Difficulty in & 45 & 9.61 \\
cognition & & \\
Confusion & 72 & 15.38 \\
Difficulty to & 27 & 5.76 \\
function & & \\
Fatigue & 18 & 3.84 \\
Palpitation & 18 & 3.84 \\
Convulsion & 9 & 1.92 \\
\hline
\end{tabular}

Multiple illicit drug use pattern are shown in Table: 2. Majority respondents were taken BZD with YABA $(32.69 \%)$, then with marijuana $(21.15 \%)$, with alcohol $(17.30 \%)$ and with phensedyl $(5.76 \%)$.

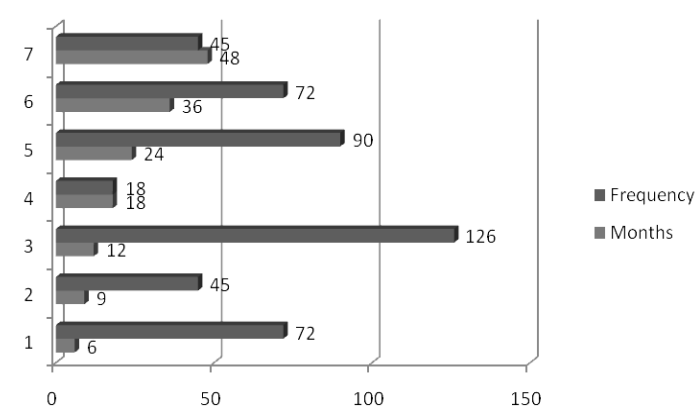

Figure 3: Duration of drug uses by Respondents.

Physiological, psychological effects and related dependence

Respondents were faced some problems after taking drugs in current context of life. Development of Antrograde amnesia (19.23\%, 90/468), confusion (9.61\%, 45/468), became ill tempered $(7.69 \%, 36 / 468)$, having difficulty in cognition $(11.53 \%, 54 / 468)$, having daytime drowsiness $(11.53 \%, 54 / 468)$, had fatigue $(9.61 \%, 45 / 468)$ are common. But 144(30.76\%) respondents didn't face any problems. Table 3 represents the tendency of the users to stop taking the drugs and face some withdrawal effects. Among 468 participants, $92.30 \%$ respondents were tried to stop taking the drug and $7.69 \%$ respondents never tried to do so. The most common withdrawal effect was insomnia $(17.30 \%)$, confusion $(15.38 \%)$, Headache $(13.46 \%)$, restlessness $(11.53 \%)$ was found. 


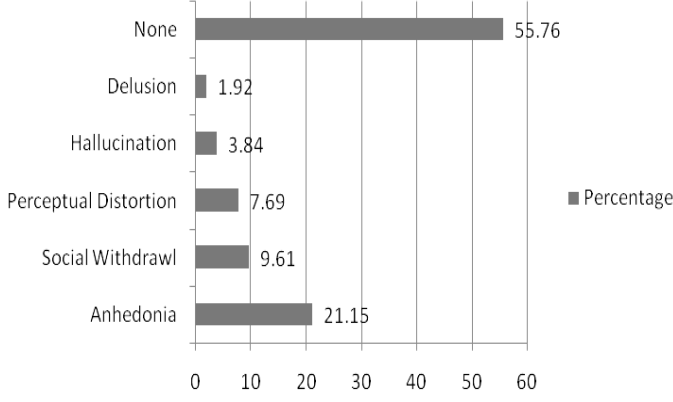

Figure 4: Development different of psychotic symptoms.

Some psychotic symptoms were developed after long term uses of BZD. Majority $(55.76 \%)$ respondents denied mentioning it, But $21.15 \%$ had anhedonia, $9.61 \%$ had social withdrawal symptoms, $7.69 \%$ had perceptual distortion and some other effects are also shown in Figure: 4.

\section{DISCUSSION}

Ojha et al., found $91 \%$ male and only $9 \%$ were female respondents shows the similarity with current study ${ }^{6}$. In Bangladesh, two different studies reported majority drug users were from age group 22-25 years ${ }^{7}$, and $64.6 \%$ of the respondents' ages were $20-24$ years $^{8}$, these findings are very much close to the age group of current study. Again, from another studies in Bangladesh found almost half (48\%) of the participants were in the age group 30-39 years ${ }^{9}$, a complete a different result of the previous findings. In 2004, Mahbubur et al., found $85.7 \%$ respondents get into consuming the drugs under the influence of friends ${ }^{3}$. Mahbuba Naznin (2010) said that $38.75 \%$ respondents were influenced by friends in her study ${ }^{10}$. Abul Hashem et al., mentioned $42.6 \%$ respondents were influenced by their peer group or friends ${ }^{8}$. All the findings strongly support the current research, because the majority $(44.23 \%)$ of respondents was influenced by friends. Neilsen et al., found almost $70 \%$ participants used BZD, as a non-prescription drug, most commonly diazepam $(55 \%)$ and alprazolam $(30 \%)$ in Queensland, Tasmania, Western Australia and Victoria ${ }^{11}$. But another study of Australia reported 13\% respondents used prescribed $\mathrm{BZD}^{12}$. In Lebanon, $\sim 20 \%$ of the young adult population is taking psychoactive substances in nonmedical reason ${ }^{13}$. Misuse of BZD by $57.2 \%$ because of workload and increasing of patients' stress, accepted by Thai doctors ${ }^{14}$. This research reveals that only $11.54 \%$ were taken BZD based on Doctors' prescription in Dhaka city.

The most noticeable feature is the common tendency of drug users to take the primary drug and mix it with the multiple drugs for concomitant use. National Institute on Drug Abuse reported the continuous abuse of prescription medications and over the counter products by Adolescent ${ }^{15}$. The current study revealed the findings of Ahad et al., who stated all the drug addicts were dependent on multiple types of drugs, most commonly cannabis (95.24\%), YABA (61.9\%), Alcohol (47.62\%), tranquilizers and other drugs (50\%) etc ${ }^{7}$. In Nepal, $86 \%$ of the sample population used opioids in combination with BZD and antihistamines ${ }^{6}$. Purposes of taking drug are more or less common in all studies. Kevin WC et al., shows in a survey that the main reasons for using BZD without a prescription are curiosity (46\%), relieving tension or anxiety $(41 \%)$ and for feeling good $(37 \%)^{1}$. Among the Lebanese BZD users, $44.4 \%$ were taking for relieving anxiety, for insomnia $(22.5 \%)$ and for depression $(16 \%)^{16}$. Only $17.0 \%$ medical students used sedative drugs at some time because of significant psychological stress in King Saud University College of Medicine in 2011 was found in different study ${ }^{17}$. Another study in Dhaka showed $31.88 \%$ users became drug addicted because they are trying to get something new ${ }^{10}$. Among all the self-reported BZD users, $60 \%$ were confirmed to leave the drug, $11 \%$ were tried and $29 \%$ had no interest to stop taking $\operatorname{drug}^{1}$. Whereas, according to the current study, $92.30 \%$ were tried to stop uses the BZD, which is a good sign for future generation and also for the policy makers. The withdrawal effects were rebound insomnia, anxiety, restlessness, BZD dependence etc. It can occur even when doses are low and consumed over a short period of time mentioned in two different studies $^{18-19}$. Abul Hashem et al., reported in their study that the misused substances are alcohol, tobacco, heroin, marijuana, choros, cocaine, morphine and YABA tablets in Dhaka city ${ }^{8}$. Mahbuba Naznin (2010) said that phencyclidine (52.5\%), Heroin (23.12\%), Charas (30\%), Marijuana (30\%), and Ganja (86.87\%) were taken by the student from different Private University of Dhaka city ${ }^{10}$. According to Ahad et al., highest $95.24 \%$ are addicted by cannabis and $61.90 \%$ involved in YABA addiction in Sylhet ${ }^{7}$. Again, Shariful et al., reported almost half of the participants $(50.8 \%)$ taken cannabis and $18.3 \%$ started with coughsyrup (phensedyl) in Dhaka'. These all studies are representing the current drug addiction picture of Bangladesh partially. Whereas, the current research emphasizes the uses of BZD; moreover the respondents were also addicted on alcohol, Yaba, Marijuana and Phensedyl simultaniously. Therefore, more study should be conducted in Bangladesh with large sample to find out the cause of addiction and how to eliminate or reduce the burden of drug addiction from this country.

\section{CONCLUSION}

Drug abuse is associated with easy access of sedative/tranquilizer, use by family member, friends or previous prescription etc. Due to lack of monitoring and easy accessibility, BZD abuse is increasing day by day in different countries of the world. The government should take strict action to regulate the availability of misused drugs through implementation of law and regulation and also should take steps to grow awareness among the people especially young about the negative impact of drugs addiction.

\section{AUTHOR'S CONTRIBUTION}

The manuscript was carried out, written, and approved in collaboration with all authors. 


\section{ACKNOWLEDGEMENTS}

The authors extend their thanks and appreciation to the Institute of Child Health and Shishu Sasthya Foundation Hospital, Dhaka, Bangladesh to provide necessary facilities for this work.

\section{CONFLICT OF INTEREST}

The authors declare that there is no conflict of interest.

\section{REFERENCES}

1. Kevin WC, Christine CB, Darlene PF, Christopher D'A, et al. Benzodiazepine use and misuse among patients in a Methadone program. BMC Psychiatry 2011; 11:90. https://doi.org/10.1186/1471-244X-11-90

2. Misuse of Prescription Drugs: a South Asia Perspective, United Nations Office on Drugs and Crime (UNDOC) 2011; 3-6.

3. Rahman M, Zaman SUM, Sakamoto J, Fukui T. How much do drug abusers pay for drugs in Bangladesh? J Health, Popul Nut 2004; 22(1):98-99. PMID: 15190818

4. Frischer M, McArdle P, Crome I. The epidemiology of substance misuse in young People. Arch Dis Child 2004; 89(8):701-704. https://doi.org/10.1007/s11920-009-0053-6

5. World drug report, 2006. United Nation: 2007. United Nation Office on Drug and Crime.

6. Ojha SP, Sigdel S, Meyer-Thompson HG, Oechsler H, et al. 'South Asian Cocktail'-the concurrent use of opioids, benzodiazepines and antihistamines among injecting drug users in Nepal and associations with HIV risk behavior. Harm Reduction J 2014; 11(17):2-7. https://doi.org/10.1186/1477-7517-11-17

7. Ahad AM, Chowdhury MD, Islam BM, Alam FM. Socioeconomic status of young drug addicts in Sylhet city, Bangladesh. IOSR- J Humanities Social Sci 2017; 22(6):8491. https://doi.org/10.4172/2471-271X.1000165

8. Hashem AM and Mushahid M. Drug Addiction in Urban Life of Bangladesh: A Sociological Study for exploring the causes. Asia Paci J Multidisc Res 2017; 5(2): 1-11.

9. Islam SMS, Biswas $\mathrm{T}$, Bhuyiyan $\mathrm{AF}$, Islam $\mathrm{SM}$, et al. Injecting Drug Users and Their Health Seeking Behavior: A Cross-Sectional Study in Dhaka, Bangladesh. J Addict 2015; ID 756579:1-8. https://doi.org/10.1155/2015/756579
10. Naznin MS. Drug Addiction among undergraduate students of Private Universities in Bangladesh. Procedia Social and Behavioral Sciences 2010; 5:498-501. https://doi.org/10.1016/j.sbspro.2010.07.131

11. Nielsen S, Bruno R, Carruthers S, Fischer $\mathrm{J}$, et al. Investigation of pharmaceutical misuse amongst drug treatment clinics, Final Report, Melbourne: Turning point Alcohol and Drug Center 2008

12. Loxly W. Benzodiazepine use and harms among police detainees in Australia. Trends and issues in crime and criminal justice 2007; 336:1-6.

13. Ghandour LA, El Sayed DS and Martins SS. Prevalence and patterns of commonly abused psychoactive prescription drugs in a sample of university students from Lebanon: an Opportunity for cross-cultural comparisons. Drug Alcohol Depend 2012; 121(1-2):110- 117. https://doi.org/10.1016/j.drugalcdep.2011.08.021

14. Srisurapanont M, Garner P, Critchley J and Wongpakaran N. Benzodiazepine prescribing Behavior and attitudes: A survey among general practitioners practicing in northern Thailand. BMC Fam Pract 2005; 6: 27. https://doi.org/10.1186/1471-2296-6-27

15. Extent of the Prescription Drug Abuse Problem. The Community Epidemiology Work Group (CEWG). National Institute on Drug Abuse (NIDA) 2006:3-5.

16. Wijdan HR, Ghada MEK, Mary ED and Marwan ST. Prescription patterns of Benzodiazepines in the Lebanese adult population: A cross-sectional Study. Neuropsychiatr Dis Treat 2016; 12: 2299-2305. https://doi.org/10.2147/NDT.S113078

17. Al-Sayed AA, Al-Rashoudi AH, Al-Eisa AA, Addar AM, et al. Sedative drug use among King Saud University medical students: a cross-sectional sampling study. Depression Research and Treatment 2014. ID 378738. https://doi.org/10.1155/2014/378738

18. Fang SY, Chen CY, Chang IS, Wu EC, et al. Predictors of the Incidence and discontinuation of long-term use of benzodiazepines: a population-based study. Drug Alcohol Depend 2009; 104(1-2):140-146. https://doi.org/10.1016/j.drugalcdep.2009.04.017

19. Lader MH, Ron M and Petursson H. Computed axial brain tomography in long-term benzodiazepine users. Psychological Medicine 1984; 14:203-206. https://doi.org/10.1017/s0033291700003214 